\title{
Correction to: Towards robust voice pathology detection
}

\section{Investigation of supervised deep learning, gradient boosting, and anomaly detection approaches across four databases}

\section{Pavol Harar $^{1}$ (D) $\cdot$ Zoltan Galaz $^{1} \cdot$ Jesus B. Alonso-Hernandez $^{2} \cdot$ Jiri Mekyska $^{1} \cdot \operatorname{Radim~Burget}^{1} \cdot$ Zdenek Smekal ${ }^{1}$}

Received: 23 August 2019/Accepted: 26 August 2019/Published online: 14 September 2019

(C) Springer-Verlag London Ltd., part of Springer Nature 2019

\section{Correction to: Neural Computing and Applications https://doi.org/10.1007/ s00521-018-3464-7}

The Table 3 was published incorrectly in the original publication of the article. The correct version of Table 3 is given here.

Table 3 Number of chunks used in the experiments

\begin{tabular}{lrrrrr}
\hline Database & $H(M)$ & $P(M)$ & $H(F)$ & $P(F)$ & Total \\
\hline AVPD & 625 & 509 & 872 & 804 & 2810 \\
MEEI & 126 & 114 & 185 & 168 & 593 \\
PDA & 1158 & 331 & 5 & 605 & 2099 \\
SVD & 400 & 645 & 624 & 871 & 2540 \\
Total & 2309 & 1599 & 1686 & 2448 & 8042 \\
\hline
\end{tabular}

The original article can be found online at https:// doi.org/10.1007/s00521-018-3464-7.

\section{Pavol Harar}

pavol.harar@vut.cz

1 Brno University of Technology, Technicka 3082/12, 61600 Brno, Czech Republic

2 Institute for Technological Development and Innovation in Communications (IDeTIC), University of Las Palmas de Gran Canaria, Parque Científico Tecnológico de la ULPGC, Polivalente II, Planta 2, 35017 Las Palmas de Gran Canaria, Spain
The original article has been corrected.

Publisher's Note Springer Nature remains neutral with regard to jurisdictional claims in published maps and institutional affiliations. 